\title{
Response of Alveolar Macrophages to Inhaled Particulates
}

\author{
Martina Dörger Fritz Krombach \\ Institute for Surgical Research, University of Munich, Germany
}

\section{Key Words}

Alveolar macrophages . Clearance of inhaled particulates $\cdot$ Reactive nitrogen and oxygen species

Pulmonary diseases associated with inhalation of environmental or occupational particulates can be endpoints of a chronic inflammatory process in which alveolar macrophages (AM) play a pivotal role [1]. Figure 1 shows a 'smiling' human AM found in a bronchoalveolar lavage specimen [2]. AM are located in the alveolus, persistently exposed to pollute air, and serve as a first line of defense against inhaled soluble and particulate matter [3]. The biological processes involved in particulate-induced activation of AM include interactions of particulates with the cell membrane, subsequent stimulation of signal transduction pathways, activation of gene transcription, generation of reactive oxygen and nitrogen species, and secretion of proinflammatory mediators. Numerous studies have shown that different types of inhaled particulates can elicit diverse cellular and molecular responses in AM.

Localized on the epithelial surface within the alveolar surfactant film, AM have a unique position in the body [4-6]. AM are the only macrophages in the body that are exposed to an aerobic environment with an $\mathrm{O}_{2}$ partial pressure of about 100 Torr. AM have a rate of respiration at rest an order of magnitude greater than other cells [7]. AM play a complex and central role in regulating the

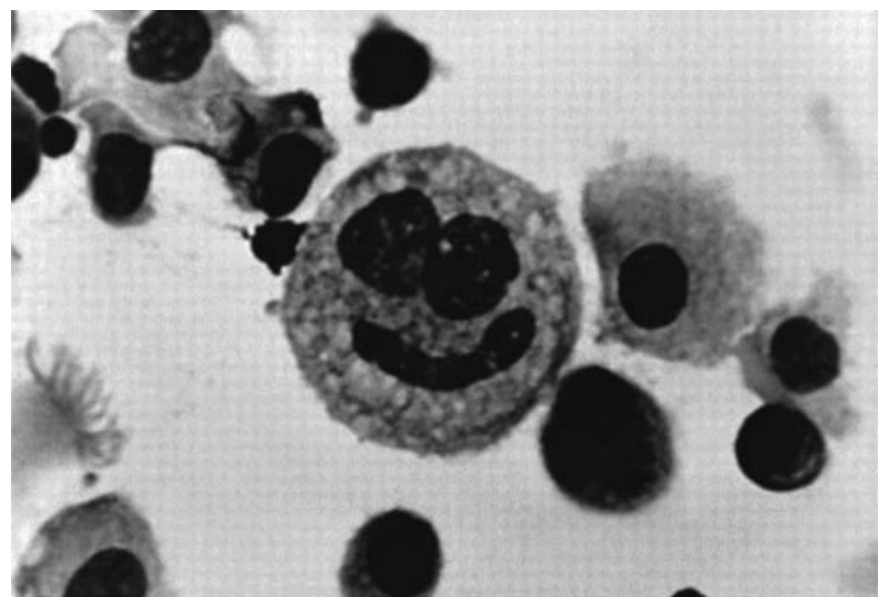

Fig. 1. 'Smiling' alveolar macrophage. A photomicrograph of a bronchoalveolar lavage specimen shows a human alveolar macrophage with a segmented nucleus (Giemsa stain, × 400; Copyright $^{\odot} 1998$ Massachusetts Medical Society. All rights preserved) [2].

immune response [4]. Their responsibility in host defense is manifold, including clearance and phagocytosis of inhaled particulates, accessory cell function in immune responses, and recruitment and activation of other inflammatory cells. To follow these duties adequately, AM are able to move to regions where they are needed, to phagocytose, and to release a broad armamentarium of mediators, such as reactive oxygen and nitrogen species, cytokines, chemokines, eicosanoids, and complement factors [8].

\section{KARGER \\ Fax +41613061234 E-Mail karger@karger.ch www. karger.com}

\author{
Prof. Dr. Fritz Krombach \\ Institute for Surgical Research, Marchioninistrasse 27 \\ D-81366 Munich (Germany) \\ Tel. +49 897095 4359, Fax +49 8970954353 \\ E-Mail krombach@icf.med.uni-muenchen.de
}



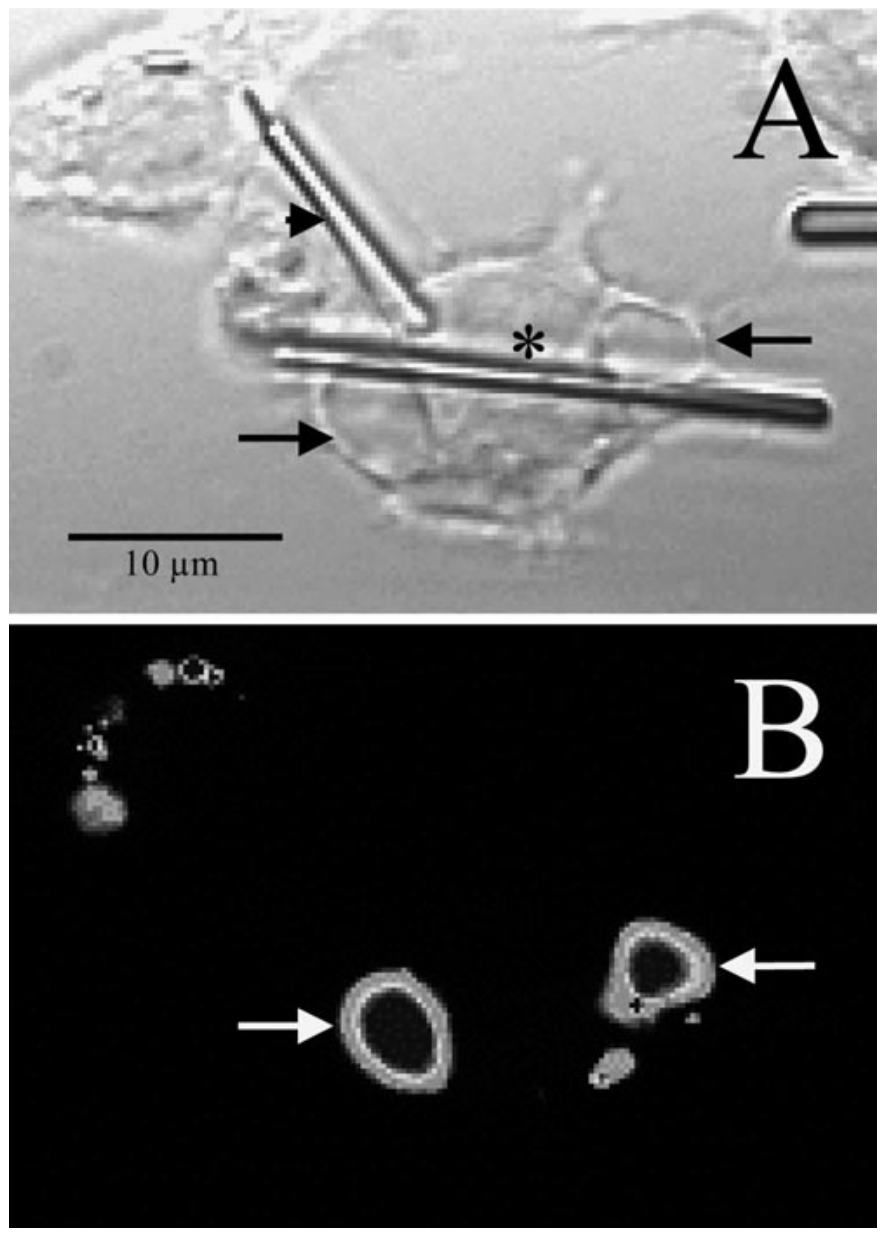

Fig. 2. Murine RAW-264.7 macrophage attempting 'frustrated' phagocytosis of a long $(>20 \mu \mathrm{m})$ mineral fiber (unpublished observation). A A light microscopic image shows two large vacuoles (arrows) localized in close vicinity of both the fiber (asterisk) and the plasma membrane. A second fiber (arrow head) appears to be just attached to the macrophage surface, without inducing a phagocytic response. B A fluorescence microscopic image after staining of the cells with LysoSensor ${ }^{\mathrm{TM}}$ Yellow/Blue DND-160, a fluorescent $\mathrm{pH}$ indicator that partitions into acidic organelles, demonstrates low $\mathrm{pH}(<5)$ in these vacuoles, suggesting formation of 'giant' (phago)lysosomes.

\section{Phagocytosis and Clearance of Inhaled Particulates}

Phagocytosis of particulates comprises a number of integrated steps, including opsonization, chemotaxis, attachment to the cell membrane, and engulfment of the particulate [4]. The recruitment of AM to the sites where asbestos fibers deposit in the lung depends on the ability of asbestos fibers to activate complement to form the chemoattractant C5a [9]. Other types of particulates, such as titanium dioxide, are only poorly effective to cause C5a generation and, therefore, are only rarely phagocytosed by AM [10]. Particulates can interact with the cell membrane either directly or indirectly through opsonization. The ability of AM to phagocytose opsonized particulates is mediated by surface receptors, in particular by Fc receptors and complement receptors [11]. Unopsonized material will be ingested by interaction with scavenger-type receptors [12, 13]. It has been suggested that the ingestion of opsonized particulates via $\mathrm{Fc}$ receptors activates $\mathrm{AM}$ to release inflammatory cytokines and reactive oxygen species. This process consequently results in pulmonary inflammation, whereas the phagocytosis of unopsonized particulates induces only minimal activation of AM [14]. 'Frustrated' or attempted phagocytosis of long mineral fibers (fig. 2) can lead to the release of great amounts of reactive oxygen species by AM over a prolonged period of time [15].

Particulate-loaded AM have to be cleared from the lung. The predominant mechanism is the transport of $\mathrm{AM}$ with their ingested particulates up the conducting airways [4]. Studies have also suggested that a proportion of particulates remains sequestered in AM for extended periods, presumably as a consequence of 'redistribution' of particulates among AM [16]. This might happen as the result of exocytosis of particulates or by release of particulates from lysed senescent $\mathrm{AM}$ and subsequent phagocytosis by new AM. Although the clearance mechanisms are comparable among humans and rodents, the macrophage-mediated clearance in humans is about an order of magnitude lower than in mice, hamsters, and rats [17]. We have observed differences in the phagocytic response of AM from rats and hamster, two rodent species that are well-known for their disparate pulmonary response to inhaled particulates. A significantly higher percentage of rat AM than of hamster AM underwent frustrated phagocytosis of mineral fibers, associated with a greater release of reactive oxygen species by rat AM compared to hamster AM. In contrast, a higher percentage of hamster AM than of rat AM completely phagocytosed mineral fibers [18], which may result in a better clearance of inhaled mineral fibers from hamster lungs than from rat lungs. High lung burden with particulates contributes to the phenomenon of particle 'overload' [4] that ends in the impairment of AM to translocate to the mucociliary escalator [19]. Interestingly enough, also high concentrations of innocuous particulates contribute to increased AM accumulation, sustained inflammation, and enhanced cell proliferation [20]. In addition to translocation of particle-loaded AM up to the conducting air- 
ways, intracellular dissolution of particulates plays a substantial role in lung clearance [21].

\section{Generation of Reactive Nitrogen and Oxygen Species}

Reactive oxygen and nitrogen species have been implicated in the pathogenesis of particulate-mediated pulmonary diseases [22]. Enhanced or prolonged production and release of reactive oxygen and nitrogen species by AM can result in direct lung tissue damage by lipid peroxidation, inactivation of enzymes, and DNA oxidation [23]. Indirectly, reactive oxygen species can activate signal transduction pathways via kinases and transcription factors [24]. These processes result in a complex cascade of events that may contribute to the development of pulmonary disorders.

Upon phagocytosis, various particulates, including titanium dioxide [25], quartz [26], carbon black [25], asbestos fibers [27], and synthetic vitreous fibers [28] induce $\mathrm{AM}$ to release reactive oxygen species by activating the NADPH oxidase. Inhaled particulates can be modified by components of the alveolar lining fluid which may alter the bioactivity of the particulates. AM release significantly greater amounts of superoxide anions upon exposure to IgG-opsonized silica particulates compared to uncoated silica particulates [29]. Similarly, coating of asbestos and various synthetic vitreous fibers with immunoglobulin enhances the release of reactive oxygen species by AM [28].

There is an increasing body of evidence that exposure to asbestos fibers induces the release of reactive nitrogen species by AM. Kagan and coworkers reported that the number of inducible nitric oxide synthase (iNOS)-positive AM increased and that the production of the stable oxidation product of nitric oxide, nitrite, was significantly enhanced by AM upon in vivo and in vitro exposure to crocidolite and chrysotile fibers [30, 31]. Moreover, the levels of nitrite and nitrate were elevated in culture medium of AM exposed to crocidolite and chrysotile fibers, along with an increased steady-state mRNA level of iNOS, but without detectable iNOS protein levels [32]. Others observed that exposure to chrysotile, but not to crocidolite and amosite fibers induced nitric oxide formation by AM [33]. Exposure to crystalline silica, carbonyl iron, coal mine dusts, and titanium dioxide has also been shown to result in iNOS mRNA and protein expression as well as enhanced production of nitric oxide by AM [34, $35]$.

Alveolar Macrophages and Inhaled

Particulates

\section{Release of Cytokines and Eicosanoids}

AM are able to release a broad spectrum of proinflammatory cytokines that are able to mediate the recruitment and activation of other inflammatory cells, stimulation of eicosanoid biosynthesis, and cell proliferation and growth [36]. A crucial role in the development of respiratory failure has been linked to tumor necrosis factor- $\alpha(\mathrm{TNF}-\alpha)$, interleukin-1 (IL-1), and interleukin-6 (IL-6). Several investigators demonstrated that AM produce enhanced levels of TNF- $\alpha$ upon in vivo and in vitro exposure to fibrogenic particulates, such as chrysotile and crocidolite asbestos, silica particulates, and coal mine dusts [37, 38]. In contrast, titanium dioxide particulates, very short asbestos fiber preparations, and diesel dust had no effect on TNF- $\alpha$ production by AM [26, 38]. Conflicting data have been reported for the particulate-induced generation of IL-1 and IL-6 in vivo and in vitro. Whereas Lemaire and Quellet [38] found an enhanced release of IL-1 and IL-6 by AM upon intratracheal instillation of asbestos fibers, others reported that neither asbestos fibers nor silica or titanium dioxide affected the production of IL-1 and IL-6 by $\mathrm{AM}$ in vitro [26, 37].

In the pathogenesis of particulate-induced lung diseases, other AM-derived cytokines may also be involved, such as macrophage inflammatory proteins 1 and 2 (MIP1, MIP-2) [14] and interleukin-8 (IL-8) [39]. In addition to TNF- $\alpha$ and IL-1, which are well-known macrophagederived growth factors [40], particulate-exposed AM also release platelet-derived growth factor (PDGF) [41] and fibroblast growth factor (FGF) [42], secretory products that cause enhanced proliferation of fibroblasts. Fibronectin, another growth-regulating protein, has also been shown to be produced by AM upon exposure to asbestos, quartz, and coal mine dusts [43].

Phagocytosis of inhaled particulates by AM triggers the synthesis and release of arachidonic acid metabolites, such as leukotriene $\mathrm{B}_{4}\left(\mathrm{LTB}_{4}\right)$ and prostaglandin $\mathrm{E}_{2}$ $\left(\mathrm{PGE}_{2}\right)$. While both mediators are known to have chemotactic activities, $\mathrm{LTB}_{4}$ stimulates the secretory response of inflammatory cells, whereas $\mathrm{PGE}_{2}$ is considered to have downregulatory effects on inflammatory cell function [44]. There are a number of studies indicating that $\mathrm{LTB}_{4}$ produced by AM is closely associated with the inflammatory response caused by inhalation of various particulates. Koren et al. [44] demonstrated an increased $\mathrm{LTB}_{4}$ release by AM upon in vitro exposure to silica, asbestos fibers, and carbonyl iron. Others reported that asbestos fibers induced an enhanced release of $\mathrm{PGE}_{2}$ as well as an increased $\mathrm{LTB}_{4}$ production by $\mathrm{AM}$ in vitro $[45,46]$.

Eur Surg Res 2002;34:47-52 


\section{Second Messengers and Transcription Factors}

The activation of signal transduction pathways through receptor-dependent mechanisms cause a change in the level of second messengers with decisive effects on cell function. The second messenger system comprises several intracellular mediators, such as inositol trisphosphate, cyclic adenosine monophosphate, diacylglycerol, and calcium. Alterations in the intracellular calcium concentration can mediate several calcium-dependent cellular events that may directly or indirectly affect cellular physiological functions. Various studies indicated that mineral particulates induce increases in the intracellular calcium concentration. It has been demonstrated that quartz [47], asbestos fibers [48], and synthetic vitreous fibers [49] cause a dose- and time-dependent increase in the intracellular calcium concentration in AM.

Upon exposure to particulates, AM can be induced to release certain cytokines, growth factors, and radicals. In many cases, the production of these mediators is associated with an earlier de novo synthesis of the molecules. Gene transcription is regulated by transcription factors; one well-known early response gene transcription factor is nuclear factor-kappaB (NF- $\kappa \mathrm{B})$ that appears to be important for the expression of many inflammation-associated genes. Increased gene expression of IL-1, IL- 6 , and TNF- $\alpha$ has been observed in AM exposed to asbestos fibers, diesel soot particles, and titanium dioxide along with an enhancement of NF- $\kappa \mathrm{B}$ gene transcription [50]. It has been suggested that reactive oxygen species are implicated in the activation of both NF- $\kappa \mathrm{B}$ and another transcription factor, activator protein-1 (AP-1) [50]. We and others have demonstrated that exposure of rat AM to inhaled toxicants induces increased intracellular production of reactive oxygen species along with an activation of NF- $\mathrm{\kappa B}$ and AP-1 [51, 52].

\section{Species Differences}

Several animal models have been used to evaluate the harmful potential of inhaled particulates. However, differences have been identified in the way species respond to inhaled particulates with the underlying reasons still unknown [53]. If comparative studies are to be used to predict biological responses in humans, then an improved knowledge of species similarities and differences is essential. Investigations of Warheit and Hartsky [54] demonstrated differences in the macrophage-mediated clearance response to inhaled particulates among rats, mice, ham- sters, and guinea pigs. Rat AM migrated best to complement-dependent chemotactic factors, and this was correlated with an increased number and percentage of phagocytic macrophages upon exposure to carbonyl iron particulates in vivo. In contrast, hamster AM appeared to be recruited to sites of particle deposition by a non-complement-mediated mechanism. Moreover, it has been suggested that species variations in response to inhaled particulates may be related to differences in the size of AM [36].

Our own studies demonstrated differences in the size of AM from rats, hamsters, monkeys, and humans, indicating that the number and size range of particulates which can be phagocytosed by AM vary among the species [55]. Likewise, we found species differences in the antioxidative and oxidative capacity of AM from rats and hamsters [56] and in the ability of AM to release nitric oxide upon stimulation $[57,58]$. Regarding the role nitric oxide plays in the oxidative stress caused by inhaled particulates, such differences are suggested to contribute to the disparate pulmonary response of rats and hamsters to mineral fibers, diesel soot, and pure oxygen [53, 59, 60].

\section{Summary}

AM occupy a central role in host defense upon inhalation of environmental and occupational particulates. The functions of AM are manifold, including phagocytosis and clearance of particulates, accessory cell function, and recruitment and activation of other inflammatory cells. The phagocytosis of particulates and the subsequent activation of signal transduction pathways in AM, such as second messengers and transcription factors, lead to the production of potent mediators, including reactive oxygen and nitrogen species, cytokines (TNF- $\alpha$, IL-1, and IL6 ), growth factors (PDGF and FGF), eicosanoids $\left(\mathrm{LTB}_{4}\right.$ and $\mathrm{PGE}_{2}$ ), and several others substances. Uncontrolled and prolonged production of these effector molecules by AM can mediate tissue injury and might, therefore, contribute to the pathogenesis of particulate-induced pulmonary diseases. 


\section{References}

1 McClellan RO: Use of mechanistic data in assessing human risks from exposure to particles. Environ Health Perspect 1997;105(suppl 5):1363-1372

2 Paraf F: Smiling alveolar macrophage. N Engl J Med 1998;339:1896

3 Gardner DE: Alterations in macrophage functions by environmental chemicals. Environ Health Perspect 1984;55:343-358.

4 Lehnert BE: Pulmonary and thoracic macrophage subpopulations and clearance of particles from the lung. Environ Health Perspect 1992;97:17-46.

5 Dörger M, Münzing S, Allmeling A-M, Messmer K, Krombach F: Phenotypic and functional differences between rat alveolar, pleural, and peritoneal macrophages. Exp Lung Res 2001; 27:65-76.

6 Krombach F, Gerlach T, Padovan C, Burges A, Behr J, Beinert T, Vogelmeier C: Characterization and quantification of alveolar monocytes in patients with chronic inflammatory lung disease. Eur Respir J 1996;9:984-991.

7 Fels AO, Cohn ZA: The alveolar macrophage. J Appl Physiol 1986;60:353-369.

8 Sibille Y, Reynolds HY: Macrophages and polymorphonuclear neutrophils in lung defense and injury. Am Rev Respir Dis 1990;141:471501.

9 Warheit DB, Overby LH, George G, Brody AR: Pulmonary macrophages are attracted to inhaled particles through complement activation. Exp Lung Res 1988;14:51-66.

10 Oberdörster G, Ferin J, Gelein R, Soderholm $\mathrm{SC}$, Finkelstein $\mathrm{J}$ : Role of the alveolar macrophage in lung injury: Studies with ultrafine particles. Environ Health Perspect 1992;97:193199.

11 Brown EJ: Phagocytosis. Bioessays 1995;17: 109-117.

12 Goldsmith CA, Frevert C, Imrich A, Sioutas C, Kobzik L: Alveolar macrophage interaction with air pollution particles. Environ Health Perspect 1997; 105(suppl 5):1191-1195.

13 Palecanda A, Paulauskis JD, Al-Mutairi E, Imrich A, Qin G, Suzuki H, Kodama T, Tryggvason K, Koziel H, Kobzik L: Role of the scavenger receptor MARCO in alveolar macrophage binding of unopsonized environmental particles. J Exp Med 1999;189:1-10.

14 Kobzik L, Huang S, Paulauskis JD, Godleski JJ: Particle opsonization and lung macrophage cytokine response. In vitro and in vivo analysis. J Immunol 1993; 151:2753-2759.

15 Dörger M, Münzing S, Allmeling A-M, Messmer K, Krombach F: Differential responses of rat alveolar and peritoneal macrophages to man-made vitreous fibers in vitro. Environ Res 2001;85:207-214.

16 Lay JC, Bennett WD, Kim CS, Devlin RB, Bromberg PA: Retention and intracellular distribution of instilled iron oxide particles in human alveolar macrophages. Am J Respir Cell Mol Biol 1998;18:687-695.
17 Kreyling W, Scheuch G: Clearance of particles deposited in the lungs; in Heyder J, Gehr P (eds): Particle Lung Interactions. New York, Marcel Dekker, 2000, pp 323-376.

18 Dörger M, Münzing S, Allmeling A-M, Krombach F: Comparison of the phagocytic response of rat and hamster alveolar macrophages to man-made vitreous fibers in vitro. Hum Exp Toxicol 2000; 19:635-640.

19 Hext PM: Current perspectives on particulate induced pulmonary tumours. Hum Exp Toxicol 1994; 13:700-715.

20 Warheit DB, Hansen JF, Yuen IS, Kelly DP, Snajdr SI, Hartsky MA: Inhalation of high concentrations of low toxicity dusts in rats results in impaired pulmonary clearance mechanisms and persistent inflammation. Toxicol Appl Pharmacol 1997;145:10-22.

21 Kreyling WG: Intracellular particle dissolution in alveolar macrophages. Environ Health Perspect 1992;97:121-126.

22 Li XY, Gilmour PS, Donaldson K, MacNee W: Free radical activity and pro-inflammatory effects of particulate air pollution (PM10) in vivo and in vitro. Thorax 1996;51:1216-1222.

23 Sies H: Oxidative stress: Oxidants and antioxidants. Exp Physiol 1997;82:291-295.

24 Martin LD, Krunkosky TM, Dye JA, Fischer BM, Jiang NF, Rochelle LG, Akley NJ, Dreher KL, Adler KB: The role of reactive oxygen and nitrogen species in the response of airway epithelium to particles. Environ Health Perspect 1997;105(suppl 5):1301-1307.

25 Rahman Q, Norwood J, Hatch G: Evidence that exposure of particulate air pollutants to human and rat alveolar macrophages leads to differential oxidative response. Biochem Biophys Res Commun 1997;240:669-672.

26 Becker S, Soukup JM, Gilmour MI, Devlin RB: Stimulation of human and rat alveolar macrophages by urban air particles: Effects on oxidant radical generation and cytokine production. Toxicol Appl Pharmacol 1996;141:637648.

27 Hansen K, Mossman BT: Generation of superoxide from alveolar macrophages exposed to asbestiform and nonfibrous particles. Cancer Res 1987;47:1681-1686.

28 Donaldson K, Hill IM, Beswick PH: Superoxide anion release by alveolar macrophages exposed to respirable industrial fibers: Modifying effect of fibre opsonization. Exp Toxicol Pathol 1995;47:229-231.

29 Perkins RC, Scheule RK, Holian A: In vitro bioactivity of asbestos for the human alveolar macrophage and its modification by IgG. Am J Respir Cell Mol Biol 1991;4:532-537.

30 Thomas G, Ando T, Verma K, Kagan E: Asbestos fibers and interferon-gamma up-regulate nitric oxide production in rat alveolar macrophages. Am J Respir Cell Mol Biol 1994;11: 707-715.

31 Tanaka S, Choe N, Hemenway DR, Zhu S, Matalon S, Kagan E: Asbestos inhalation induces reactive nitrogen species and nitrotyrosine formation in the lungs and pleura of the rat. J Clin Invest 1998;102:445-454.
32 Quinlan TR, BeruBe KA, Hacker MP, Taatjes DJ, Timblin CR, Goldberg J, Kimberly $\mathrm{P}$, O'Shaugnessy PO, Hemenway D, Torino J, Jiminez LA, Mossman BT: Mechanisms of asbestos-induced nitric oxide production by rat alveolar macrophages in inhalation and in vitro models. Free Radic Biol Med 1998;24:778788.

33 Iguchi $\mathrm{H}$, Kojo S, Ikeda M: Nitric oxide (NO) synthase activity in the lung and NO synthesis in alveolar macrophages of rats increased on exposure to asbestos. J Appl Toxicol 1996;16: 309-315.

34 Castranova V, Huffmann LJ, Judy DJ, Bylander JE, Lapp LN, Weber SL, Blackford JA, Dey RD: Enhancement of nitric oxide production by pulmonary cells following silica exposure. Environ Health Perspect 1998;106(suppl 5): 1165-1169.

35 Blackford JA Jr, Jones W, Dey RD, Castranova $\mathrm{V}$ : Comparison of inducible nitric oxide synthase gene expression and lung inflammation following intratracheal instillation of silica, coal, carbonyl iron, or titanium dioxide in rats. J Toxicol Environ Health 1997;51:203-218.

36 Fubini B, Aust AE, Bolton RE, Borm PJ, Bruch J, Ciapetti G, Donaldson K, Elias Z, Gold J, Jaurand M-C, Kane AB, Lison D, Muhle H: Non-animal tests for evaluating the toxicity of solid xenobiotics. ATLA 1998;26:579-617.

37 Driscoll KE, Carter JM, Hassenbein DG, Howard B: Cytokines and particle-induced inflammatory cell recruitment. Environ Health Perspect 1997;105(suppl 5):1159-1164.

38 Lemaire I, Ouellet S: Distinctive profile of alveolar macrophage-derived cytokine release induced by fibrogenic and nonfibrogenic mineral dusts. J Toxicol Environ Health 1996;47: 465-478.

39 Drumm K, Buhl R, Kienast K: Additional NO exposure induces a decrease in cytokine specific mRNA expression and cytokine release of particle and fibre exposed human alveolar macrophages. Eur J Med Res 1999;4:59-66.

40 Adamson IYR, Bowden DH: Pulmonary reaction to long and short asbestos fibers is independent of fibroblast growth factor production by alveolar macrophages. Am J Pathol 1990; 137:523-529.

41 Bonner JC, Osornio VA, Badgett A, Brody AR Differential proliferation of rat lung fibroblasts induced by the platelet-derived growth factor$\mathrm{AA},-\mathrm{AB}$, and $-\mathrm{BB}$ isoforms secreted by rat alveolar macrophages. Am J Respir Cell Mol Biol 1991;5:539-547.

42 Bissonnette E, Rola PM: Pulmonary inflammation and fibrosis in a murine model of asbestosis and silicosis. Possible role of tumor necrosis factor. Inflammation 1989;13:329-339.

43 Davies R, Erdogdu G: Secretion of fibronectin by mineral dust-derived alveolar macrophages and activated peritoneal macrophages. Exp Lung Res 1989;15:285-297. 
44 Koren HS, Joyce M, Devlin RB, Becker S, Driscoll K, Madden MC: Modulation of eicosanoid production by human alveolar macrophages exposed to silica in vitro. Environ Health Perspect 1992;97:77-83.

45 Dubois CM, Bissonnette E, Rola PM: Asbestos fibers and silica particles stimulate rat alveolar macrophages to release tumor necrosis factor. Autoregulatory role of leukotriene B4. Am Rev Respir Dis 1989;139:1257-1264.

46 Bissonnette E, Carre B, Dubois C, Rola PM: Inhibition of alveolar macrophage cytotoxicity by asbestos: Possible role of prostaglandins. J Leukoc Biol 1990;47:129-134.

47 Gercken G, Berg I, Dörger M, Schlüter T: Mechanisms of particle-induced activation of alveolar macrophages. Toxicol Lett 1996;88: 121-129.

48 Wang QE, Han $\mathrm{CH}$, Wu WD, Wang HB, Liu SJ, Kohyama N: Biological effects of manmade mineral fibers (I) - Reactive oxygen species production and calcium homeostasis in alveolar macrophages. Ind Health 1999;37:6267.

49 Drumm K, Oettinger R, Smolarski R, Bay M, Kienast $\mathrm{K}$ : In vitro study of human alveolar macrophages inflammatory mediator transcriptions and releases induced by soot FR 101, Printex 90, titandioxide and Chrysotile B. Eur J Med Res 1998;3:432-438.
50 Sen CK, Packer L: Antioxidant and redox regulation of gene transcription. FASEB J 1996;10: 709-720.

51 Pepperl S, Dörger M, Ringel F, Kupatt C, Krombach F: Hyperoxia upregulates the NO pathway in alveolar macrophages in vitro: Role of AP-1 and NF-kappaB. Am J Physiol Lung Cell Mol Physiol 2001;280:L905-L913.

52 Gilmour PS, Brown DM, Beswick PH, MacNee W, Rahman I, Donaldson K: Free radical activity of industrial fibers: Role of iron in oxidative stress and activation of transcription factors. Environ Health Perspect 1997;105 (suppl 5):1313-1317.

53 Warheit DB, Hartsky M: Influences of gender, species, and strain differences in pulmonary toxicological assessments of inhaled particles and/or fibers; in Mohr U (ed): Toxic and Carcinogenic Effects of Solid Particles in the Respiratory Tract. Washington, ILSI Press, 1994, pp 253-265.

54 Warheit DB, Hartsky MA: Role of alveolar macrophage chemotaxis and phagocytosis in pulmonary clearance responses to inhaled particles: Comparisons among rodent species. Microsc Res Tech 1993;26:412-422.

55 Krombach F, Münzing S, Allmeling A-M, Gerlach JT, Behr J, Dörger M: Cell size of alveolar macrophages: an interspecies comparison. Environ Health Perspect 1997;105(suppl 5): 1261-1263.
56 Dörger M, Allmeling A-M, Neuber A, Behr J, Rambeck W, Krombach F: Interspecies comparison of rat and hamster alveolar macrophage antioxidative and oxidative capacity. Environ Health Perspect 1997;105(suppl 5): 1309-1312.

57 Dörger M, Jesch NK, Rieder G, Hirvonen MR, Savolainen K, Krombach F, Messmer K: Species differences in NO formation by rat and hamster alveolar macrophages in vitro. Am J Respir Cell Mol Biol 1997;16:413-420.

58 Jesch NK, Dörger M, Enders G, Rieder G, Vogelmeier C, Messmer K, Krombach F: Expression of inducible nitric oxide synthase and formation of nitric oxide by alveolar macrophages: An interspecies comparison. Environ Health Perspect 1997;105(suppl 5):12971300.

59 Bryan CL, Jenkinson SG: Species variation in lung antioxidant enzyme activities. J Appl Physiol 1987;63:597-602.

60 Heinrich U, Muhle H, Takenaka S, Ernst H, Fuhst R, Mohr U, Pott F, Stöber W: Chronic effects on the respiratory tract of hamsters, mice and rats after long-term inhalation of high concentrations of filtered and unfiltered diesel engine emissions. J Appl Toxicol 1986;6:383395. 